\title{
Rare Genotype of His/His in NUDT15 Codon 139 and Thiopurine-associated Adverse Events in a Case of Ulcerative Colitis
}

\author{
Kei Tomiyoshi ${ }^{1}$, Hiroki Sato ${ }^{1}$, Kentaro Tominaga ${ }^{1}$, Yuzo Kawata ${ }^{1}$, Daisuke Okamoto $^{2}$, \\ Yoichi Kakuta $^{2}$, Junji Yokoyama ${ }^{1}$ and Shuji Terai ${ }^{1}$
}

\begin{abstract}
:
Thiopurine drugs are commonly used to treat immunologic diseases. However, the narrow therapeutic safety margin demands evidence-based precision medicine approaches. NUDT15 variants are associated with thiopurine-induced adverse events, particularly in Asians. We herein report a rare genotype of His/His in NUDT15 codon 139 in a case of ulcerative colitis and review the relevant literature. The patient experienced severe thiopurine-associated adverse events, including leukopenia and alopecia. There is no literature on the His/His genotype in NUDT15 codon 139, and our case suggests cautious use or the contraindication of thiopurines for patients with this genotype.
\end{abstract}

Key words: inflammatory bowel disease, His/His genotype, NUDT15, thiopurine, leukopenia, ulcerative colitis

(Intern Med 59: 1611-1613, 2020)

(DOI: 10.2169/internalmedicine.4261-19)

\section{Introduction}

Thiopurine drugs, including 6-mercaptopurine (6-MP) and its prodrug azathioprine (AZA), are commonly used for inflammatory bowel diseases (IBDs), rheumatic disease, acute lymphoblastic leukemia, and autoimmune hepatitis. However, nucleoside diphosphate-linked moiety X-type motif 15 (NUDT15) variants are reported to show a significant association with thiopurine-induced adverse events, particularly in Asians.

NUDT15 is a 164-amino-acid protein that belongs to the nudix hydrolyses enzyme family, which mainly consists of pyrophosphohydrolases that act on nucleoside diphosphate. The function of this enzyme is to hydrolyze the thiopurine effector metabolites 6-thio-deoxy-GTP (dGTP) and 6-thioGTP, thereby limiting the efficacy of thiopurines. The NUDT15 genetic variants disrupt the function of NUDT15 to varying degrees $(1,2)$.

We previously analyzed and established a method to accu- rately identify the risk of codon 139 genotypes in adverse events associated with thiopurines in patients with IBDs, using the results of the MENDEL study in 2018 (3). However, cases with genetic variants of His/His in codon 139 were excluded. Owing to their rarity, cases with the His/His genetic variant in codon 139 have not been reported in Asian patients (Table) (1,3-7). Therefore, the treatment strategy for patients with the His/His variant in codon 139 remains unclear.

\section{Case Report}

A 40-year-old man who had been diagnosed with ulcerative colitis 6 months earlier was referred to our unit, as he was resistant to induction therapy with 5-aminosalicylic acid, followed by prednisolone and leukocytapheresis. He was hospitalized and administered $4.0 \mathrm{mg} / \mathrm{day}$ tacrolimus to resolve abdominal pain and diarrhea and was discharged with the same dose of tacrolimus and $5.0 \mathrm{mg} /$ day prednisolone. NUDT15 genetic polymorphism testing (1) revealed

${ }^{1}$ Division of Gastroenterology, Niigata University Medical and Dental Hospital, Japan and ${ }^{2}$ Division of Gastroenterology, Tohoku University Graduate School of Medicine, Japan

Received: November 26, 2019; Accepted: February 26, 2020; Advance Publication by J-STAGE: April 9, 2020

Correspondence to Dr. Hiroki Sato, pyloki-sato@med.niigata-u.ac.jp 
Table. NUDT15 Polymorphisms and Thiopurine-associated Leukopenia in Asian Patients.

\begin{tabular}{|c|c|c|c|c|c|}
\hline Reference & Diagnosis $\dagger$ & Country & $\begin{array}{l}\text { Number of } \\
\text { patients }\end{array}$ & Reported haplotype & $\begin{array}{c}\text { Possible diplotype and } \\
\text { estimated enzyme activity } \ddagger\end{array}$ \\
\hline 4 & IBD & Korea & 978 & p.Arg139Cys & $\begin{array}{l}\text { Normal: Arg/Arg, Intermediate: Arg/Cys, } \\
\text { Low: Cys/Cys (codon 139) }\end{array}$ \\
\hline 1 & ALL & $\begin{array}{l}\text { Guatemala, } \\
\text { Singapore, } \\
\text { Japan }\end{array}$ & 270 & $\begin{array}{l}\text { p.Arg139Cys } \\
\text { p.Arg139His } \\
\text { p.Val18Ile } \\
\text { p.Val18_Val19insGlyVal }\end{array}$ & $\begin{array}{l}\text { Normal: } \star 1 / \star 1 \\
\text { Intermediate: } \star 1 / \star 2, \star 1 / \star 3, \star 1 / \star 4, \star 1 / \star 5 \\
\text { Low: } \star 3 / \star 5, \star 2 / \star 3, \star 3 / \star 3\end{array}$ \\
\hline 5 & IBD & China & 732 & $\begin{array}{l}\text { p.Arg139Cys } \\
\text { p.Val18_Val19insGlyVal } \\
\text { p.Val18Ile }\end{array}$ & $\begin{array}{l}\text { Normal: } \star 1 / \star 1, \\
\text { Intermediate: } \star 1 / \star 2, \star 1 / \star 3, \star 1 / \star 5, \star 1 / \star 6 \\
\text { Low: } \star 2 / \star 3, \star 2 / \star 6, \star 3 / \star 3, \star 3 / \star 5\end{array}$ \\
\hline 3 & IBD & Japan & 1,291 & $\begin{array}{l}\text { p.Arg } 139 \text { Cys } \\
\text { p.Arg } 139 \text { His }\end{array}$ & $\begin{array}{l}\text { Normal: Arg/Arg, Arg/His, } \\
\text { Intermediate: Arg/Cys, } \\
\text { Low: Cys/His, Cys/Cys (codon 139) }\end{array}$ \\
\hline 6 & $\mathrm{AIH}$ & China & 149 & p.Arg139Cys & $\begin{array}{l}\text { Normal: Arg/Arg, Intermediate: Arg/Cys, Low: } \\
\text { Cys/Cys (codon 139) }\end{array}$ \\
\hline 7 & IBD & Japan & 1,245 & $\begin{array}{l}\text { p.Val18Ile } \\
\text { p.Val18_Val19insGlyVal } \\
\text { p.Gly17_Val18del }\end{array}$ & $\begin{array}{l}\mathrm{N}+\mathrm{N}: \star 1 / \star 1, \\
\mathrm{~N}+\mathrm{I}: \star 1 / \star 4, \star 1 / \star 5, \star 1 / \star 6, \\
\mathrm{~N}+\mathrm{L}: \star 1 / \star 2, \star 1 / \star 3, \star 1 / \star 9, \\
\mathrm{I}+\mathrm{L}: \star 3 / \star 5, \star 2 / \star 6, \star 2 / \star 5, \star 3 / \star 4, \star 2 / \star 4, \\
\mathrm{~L}+\mathrm{L}: \star 3 / \star 3, \star 2 / \star 3, \star 2 / \star 2\end{array}$ \\
\hline Our case & IBD & Japan & 1 & p.Arg139His & His/His (codon 139) \\
\hline
\end{tabular}

$\dagger$ IBD: inflammatory bowel disease, ALL: acute lymphocytic leukemia, AIH: autoimmune hepatitis

$\$ \mathrm{~N}$ : Normal, I: Intermediate, L: Low enzyme activity; for star allele-based haplotyping, refer to Fig. 2

Codons of NUDT15 gene

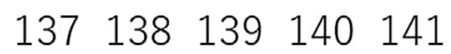

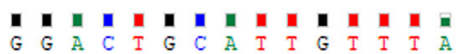

Our case

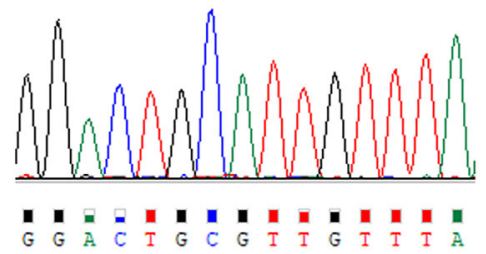

Normal

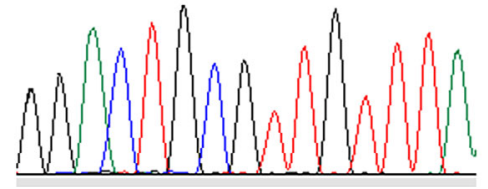

Figure 1. A Sanger sequence chromatogram around codon 139 of NUDT15. Exons 1-3 on NUDT15 were analyzed. The homozygous mutation of $\mathrm{c.416G}>\mathrm{A}$ leading to $\mathrm{p}$.Arg139His was observed in our case.

the genetic variant of His/His in codon 139. Accordingly, as maintenance therapy, AZA was started at a low dose of 25 $\mathrm{mg} /$ day and increased to $50 \mathrm{mg} /$ day after 2 weeks, based on a stable peripheral white blood cell count of $5,650 / \mu \mathrm{L}$.

However, on day 40 from the initiation of AZA therapy, he returned to our unit with severe fatigue and anorexia; a

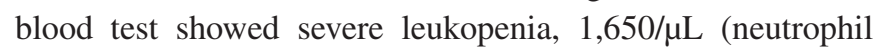
count: $21.5 / \mu \mathrm{L})$. The 6-thioguanine nucleotide level was within the therapeutic range at $72 \mathrm{pmol} / 8 \times 10^{8} \mathrm{red}$ blood cells. He suffered from severe alopecia. Upon hospitalization, all medications, including AZA, were ceased, and granulocyte colony-stimulating factor was used to increase his white blood cell count to $4,440 / \mu \mathrm{L}$. He was discharged on day 18 and commenced vedolizumab therapy at a starting dose of $300 \mathrm{mg}$ per 2 weeks that was gradually tapered to $300 \mathrm{mg}$ per 8 weeks. He remains in remission.

We analyzed the exonic sequences of NUDT15 and identified only the His/His variant (Fig. 1); no functional variants in coding regions besides His/His on codon 139 were identified.

All procedures performed in the subject were in accordance with the 1964 Declaration of Helsinki. Informed consent was obtained from the participant involved in the study.

\section{Discussion}

We herein report a rare case of ulcerative colitis with a His/His mutation; the patient had acute and severe leukopenia (white blood cell count $<2,000 / \mu \mathrm{L},<8$ weeks) along with severe alopecia. In the MENDEL study, which involved 1,291 patients with IBD with a history of thiopurine usage, Arg/Arg, Arg/His, Arg/Cys, Cys/His, and Cys/Cys genotypes in codon 139 were found in $74.2 \%, 0.5 \%, 21.3 \%, 0.2 \%$, and $3.8 \%$, respectively (3). The His/His genotype was not observed, so the frequency of this genotype was considered even rarer than those observed. According to the sequence data of 4,700 Japanese individuals in the Tohoku Medical Megabank Organization, the allele frequency of p.Arg139 His is 0.0008 , so the genotype frequency of His/His is even lower (estimated at 0.00000064) (8). 


\section{Haplotypes of NUDT15}

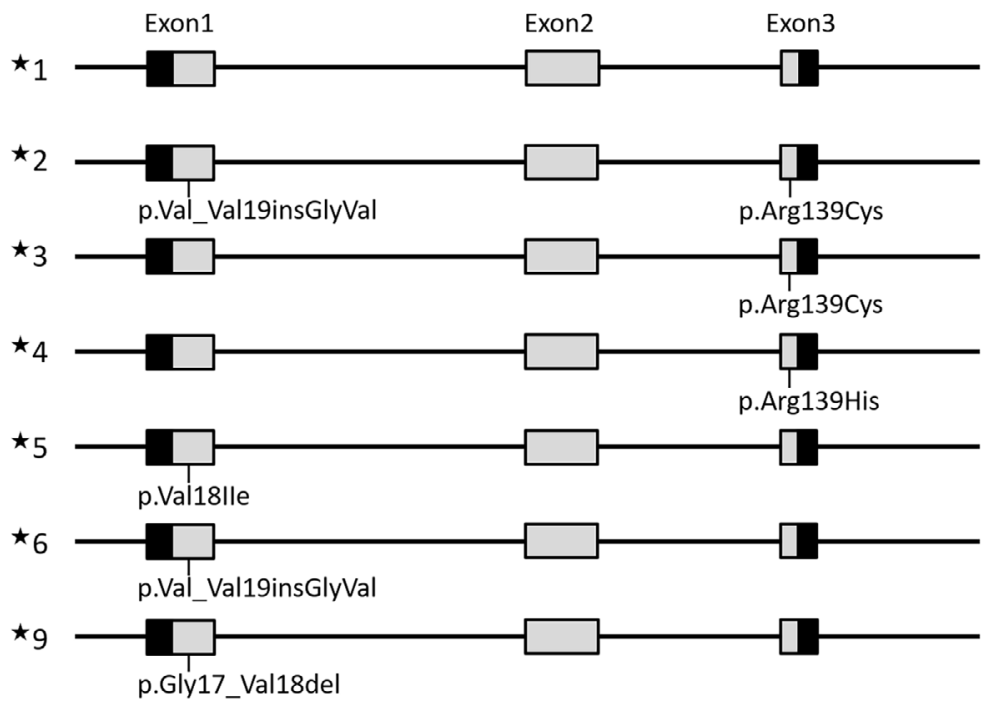

Figure 2. Star $(\star)$ allele-based haplotypes of NUDT15 reported in patients. The diplotypes described in Table are combinations of the haplotypes.

All of the haplotypes (refer to Fig. 2) and diplotypes that induce thiopurine-associated leukopenia in Asian patients are summarized in Table. The estimated enzyme activity in haplotype cases with p.Arg139His is intermediate, whereas that in diplotype cases with the codon $139 \mathrm{His} / \mathrm{His}$ genotype is predicted to be low, regardless of the codon 18 genotype. Therefore, the codon 18 genotype may be ignored when determining the risk of adverse events (7).

We suggest cautious treatment with a low dose of 6-MP (5-10 mg/day) or the contraindication of thiopurines when the Arg/Arg genotype in codon 139 is replaced by $\mathrm{Cys} / \mathrm{His}$ or Cys/Cys, respectively (3); such treatment lines are also recommended for patients with His/His. Further research will be required to clarify the risk of NUDT15-associated thiopurine-induced adverse events. Furthermore, although a case report may not determine the causal association, the accumulation of cases of this rare genotype is expected to help clarify the best management of unique cases.

The authors state that they have no Conflict of Interest (COI).

\section{Financial Support}

Sequence analyses were supported by AMED under Grant Number 19ek0410056 to Y. Kakuta.

\section{References}

1. Moriyama T, Nishii R, Perez-Andreu V, et al. NUDT15 polymor- phisms alter thiopurine metabolism and hematopoietic toxicity. Nat Genet 48: 367-373, 2016.

2. Valerie NC, Hagenkort A, Page BD, et al. NUDT15 hydrolyzes 6thio-deoxyGTP to mediate the anticancer efficacy of 6thioguanine. Cancer Res 76: 5501-5511, 2016.

3. Kakuta Y, Kawai Y, Okamoto D, et al. NUDT15 codon 139 is the best pharmacogenetic marker for predicting thiopurine-induced severe adverse events in Japanese patients with inflammatory bowel disease: a multicenter study. J Gastroenterol 53: 1065-1078, 2018.

4. Yang SK, Hong M, Baek J, et al. A common missense variant in NUDT15 confers susceptibility to thiopurine-induced leukopenia. Nat Genet 46: 1017-1020, 2014.

5. Chao K, Wang X, Cao Q, et al. Combined detection of NUDT15 variants could highly predict thiopurine-induced leukopenia in Chinese patients with inflammatory bowel disease: a multicenter analysis. Inflamm Bowel Dis 23: 1592-1599, 2017.

6. Fan X, Yin D, Men R, Xu H, Yang L. NUDT15 polymorphism confer increased susceptibility to thiopurine-induced leukopenia in patients with autoimmune hepatitis and related cirrhosis. Front Pharmacol 10: 346, 2019.

7. Kakuta Y, Izumiyama Y, Okamoto D, et al. High-resolution melt analysis enables simple genotyping of complicated polymorphisms of codon 18 rendering the NUDT15 diplotype. J Gastroenterol 55: 67-77, 2020.

8. Tadaka S, Saigusa D, Motoike IN, et al. jMorp: Japanese Multi Omics Reference Panel. Nucleic Acids Res 46: D551-D557, 2018.

The Internal Medicine is an Open Access journal distributed under the Creative Commons Attribution-NonCommercial-NoDerivatives 4.0 International License. To view the details of this license, please visit (https://creativecommons.org/licenses/ by-nc-nd/4.0/).

(C) 2020 The Japanese Society of Internal Medicine Intern Med 59: 1611-1613, 2020 